\title{
Start of Polytrauma Management in University Hospital: First Experience with Liver Trauma
}

\author{
Solvita Stabina*,**, Aleksejs Kaminskis*, Guntars Pupelis*,** \\ *Riga East Clinical University hospital Gailezers, General and Emergency Surgery Departament, Latvia \\ ** Riga Stradins University, Latvia
}

\section{SUMMARY}

Introduction. Trauma is a leading cause of death, particularly among young patients. Spleen is the most commonly damaged organ in blunt abdominal trauma and liver injury is the main cause of death.

Aim of the study. Review of the literature and recent clinical experience in the management of blunt liver injuries in the Riga East clinical university hospital.

Materials and methods. Three-year experience in the management of liver traumatic rupture was retrospectively and prospectively analysed. The study included 64 patients over 15 years of age with blunt hepatic injuries. Exclusion criteria were patients with lifeincompatible haemorrhagic shock. The Statistical analysis of the data was performed by median and mean of the Microsoft Excel 2010 and SPSS 22 version.

Results. A total of 64 patients were treated in our institution during the period from November 2010 till November 2013. Isolated liver injuries were diagnosed in 49 cases, combined liver and spleen injuries in 15 cases. Most commonly mechanism ofinjury were road traffic accidents, falls and low energy blunt traumas (criminal beaten, sports injuries);19 patients underwent laparotomy for haemostasis while nonoperative management was used in 45 patients. Haemodynamic stability of the patient and CT confirmed liver injury were the main criteria for nonoperative management. One patient died atthe time of laparotomy from injuries not compatible with life - severe head injury with basal skull fracture, aortic arc rupture, flail chest and liver and spleen injury.

Conclusions. Conservative management of liver trauma is justified in haemodynamically(HD) stable patients after thorough risk assessment and computed tomography (CT) based injury grading in centres with sufficient expertise and medical resources.

Key words: liver injury,blunt abdominal trauma, non-operative management

\section{INTRODUCTION}

Junior and adult mortality secondary to trauma is constantly high all over the globe. According to statistics from United States mortality secondary to variable type of injuries reached $50.6 \%$ among persons in age segment from 1-44 years.(9)

\section{Injury facts:}

- More than 180,000 deaths from injury each year 1 person every 3 minutes

- $\quad$ An estimated 2.8 million people hospitalized with injury each year (13)

- Violence and injuries cost more than $\$ 406$ billion in medical care and lost productivity each year (5)

According to prognosis by the year 2020, 8.4 million people may die every year from injury. Traumatic injuries will be from third to second most common cause of disability worldwide.(11) The most common mechanisms of injury are: falling from height, road accidents, blunt force trauma and barotrauma. Roadtraffic injuries are major cause of deaths worldwide including Latvia. Traffic is becoming more intense, for example, at the end of 2013, 316 cars per 1000 inhabitants were registered in Latvia, while in 2000 were registered only 237 cars per 1000 inhabitants.(7)

\section{AIM OF THE STUDY}

The aims of the study were to analyse our recent 3-year experience after start of polytrauma service in the Riga East clinical university hospital and to summarise the data from literature and existing guidelines about the management of the blunt liver injury.

\section{MATERIAL AND METHODS}

Three year experience in the management of liver traumatic rupture was retrospectively and prospectively analysed. Patients were divided in nonoperative management and operative management groups. Main demographic data, ASA score, Glasgow coma score, trauma mechanism, liver injury grade, injury severity score (ISS) and trauma score were recorded, and individual severity of the injury,treatment strategy and final outcomes were analysed comparing two groups. Haemodynamically unstable patients with positive FAST and/or CT confirmed urinary tract diaphragm or hollow viscus injury underwent urgent laparotomy. Nonoperative management (NOM) included continuous monitoring and repeated abdominal ultrasonography during the early ICU treatment period with CT control. 


\section{RESULTS}

Totally 64 patients with blunt liver trauma were treated during the period between November 2010 and November 2013, from them, 41 male patient with median age 41.9 years $(S D=15.5)$ and 23 female patients with median age 33.1 year $(S D=15.1)$ years, $p=0.031$. The most common trauma mechanisms were road traffic accidents involving the driver of the vehicle in 33 cases $(51.6 \%)$. At the next place were falls from height in 16 cases $(25 \%)$ and low energy blunt trauma in 15 cases $(23.4 \%)$.

Grade I liver injury were detected in 23 cases (35.9\%) with median ISS score 29 (IQR, 28-24) points and two of them $(8.7 \%)$ underwent surgery because of the bleeding spleen injury, 25 patients $(39.1 \%)$ were treated with grade II liver injury, median ISS score 33 (IQR, 4322 ) points, 9 of them $(36.0 \%)$ underwent surgery. Grade III injury were found in 12 cases $(18.8 \%)$, median ISS 35 (IQR, 43-23) points, 5 of them were operated. Severe grade IV liver injuries were in four cases, median ISS 44 (IQR, 62-33) and three of them underwent surgery. In all cases were done perihepatic packing and in two cases were done splenectomy, because of combined spleen injury.

From all $25(39 \%)$ patients had associated intraabdominal injuries - kidney laceration in 13 cases, pneumoperitoneum in 3 cases, mesenterial rupture in 2 cases. One patient was operated because of grade $\mathrm{V}$ kidney, grade IV pancreas, grade II liver and grade II spleen injury and one patient was operated because of diaphragm rupture.

20 years old female died 136 minutes after arrival to the hospital. She was delivered hemodynamically unstable and underwent laparotomy and abdominal packing after positive FAST. Ventricular fibrillation started atthe time of surgery and cardio pulmonary resuscitation failed.

\section{DISCUSSION}

The surface anatomy of the liver was described as early as 2000 years BC by the ancient Babylonians. Francis Glisson was the first who accurately described the vascular anatomy of the liver in 1954. Rudimentary excisions of eviscerated liver for the patient with penetrating liver injury is defined as beginning of liver surgery. The partial hepatectomy was performed to patient with self - inflicted stab wound. Operation was done by Berta in 1916, and is considered as first partial liver resection.(25) Nonoperative management for blunt liver injury firstly was described in pediatric practice in 1980, and in 1990 in adults. However first issues were addressed by the Eastern Association for the Surgery of Trauma in the Practice Management Guidelines for Nonoperative Management of Blunt Injury to the Liver and Spleen published online in 2003.(15)

One hundred seventy-six articles were identified from National Library of Medicine and the National
Institutes of Health MEDLINE database published after 1996 for blunt liver trauma. Ninety four articles were used to create Eastern Association for the Surgery of Trauma guidelines. The guidelines herald that nonoperativemanagementis thetreatment modality of choice forhemodynamicallystable patientsregardless ofthe injurydegreeandthe patient's age. Published literature and our study have shown that organ injury grade, ISS score, age and additional injuries such as kidney and spleenis not a contraindication for NOM.

Results of this study are similar to reported data from literature confirming evidence that most patients were adults and the main trauma mechanism was associated with road traffic accidents. Falls from the height were the next most often cause of liver trauma. According to data from this study liver trauma most often lead to Grade I and Grade II injuries in more than one third of cases. Less than one fifth of patients suffered Grad III injury and Grade IV injury was recognized in 6\%.(22) Majority of patient with Grade I-III injuries were managed by NOM.(21) Three out of four patients with Grade IV underwent surgery due to associated spleen injury. Main surgical procedure were Damage control perihepatic packing.(16) Maine indication for surgery was uncontrolled haemorrhage and associated organ injury.(12) One death in these series was associated with ventricular fibrillation and cardiac arrest during the damage control laparotomy and perihepatic packing Injury mechanism

The blunt liver trauma characterized by two mechanisms the deceleration and crush injury. Deceleration injuries are more typical to road traffic accidents and falls from a height. Liver parenchyma and capsule rupture is the main result of the indirect impact and usually create lacerations between the segments fifth, sixth, seventh and eighth as well as large hepatic vessels. Crush injuries following direct trauma to the liver usually damage fourth, fifth and eighth segments.(19)

\section{Injury classification (Table $\mathrm{Nl}$ )}

Liver injury ranges from a minor capsular tear, with or without parenchymal injury, to deep tear involving hepatic blood vessels. This scale is useful not only as a descriptive but also as an outcome predictor that facilitates comparisons across groups of patients. 
Table N1 Liver injury grading system

\begin{tabular}{|l|l|l|}
\hline Grade & Type & Description \\
\hline I & Haematoma & Subcapsular $<10 \%$ surface \\
\hline & Laceration & Capsular tear $<1 \mathrm{~cm}$ parenchymal depth \\
\hline II & Haematoma & Subcapsular $10-50 \%$ surface area; intraparenchymal, $<10 \mathrm{~cm}$ diameter \\
\hline III & Laceration & $1-3 \mathrm{~cm}$ parenchymal depth, $<10 \mathrm{~cm}$ in lenght \\
\hline & Haematoma & $\begin{array}{l}\text { Subcapsular }>50 \% \text { surface area or expanding, ruptured subcapsular or } \\
\text { parenchymal haematoma. Intraparenchymal haematoma } .10 \mathrm{~cm}\end{array}$ \\
\hline IV & Laceration & $>3 \mathrm{~cm}$ parenchymal depth \\
\hline V & Laceration & Parenchymal disruption $25-75 \%$ of hepatic lobe \\
\hline & Laceration & Parenchimal disruption involving $>75 \%$ of hepatic lobe \\
\hline VI & Vascular & Juxtavenous hepatic injuries \\
\hline
\end{tabular}

Diagnostic algorithm. (Figure N1)

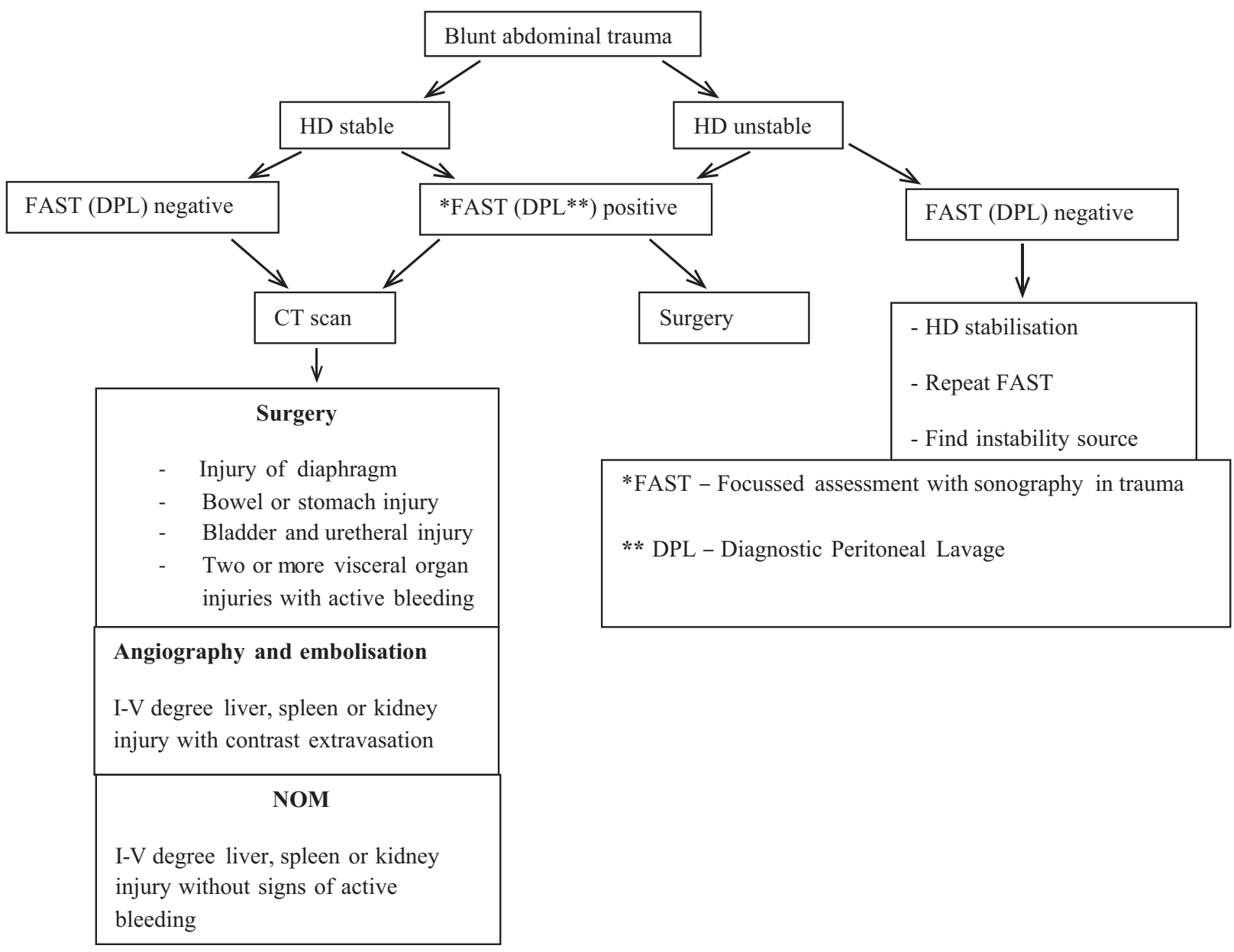

Fig. 1. Algoritm for the management of blunt abdominal trauma 
FAST. (Figure N2) Acronym FAST was defined for the first time by international consensus conference committee in 1997. The term describe the application of ultrasound in the initial evaluation of trauma patients.(2) FAST is not detailed abdominal ultrasound examination, but it helps to get around in the limited time situations.FAST scan alone has a sensitivity of $70 \%$ and specificity of $100 \%$ in combination with physical examination, the sensitivity roses up to $100 \% .(23)$ Branney and colleagues in a study on infused volumes of DPL found that only $10 \%$ of participants performing FAST could detect fluid volumes of less than $400 \mathrm{~mL}$, the mean detected volume in the peritoneal cavity was $619 \mathrm{ml}$. Von Kuenssberg, Jehle and colleagues found that the mean minimal volume of fluid needed for pelvic ultrasound is $157 \mathrm{~mL}$.

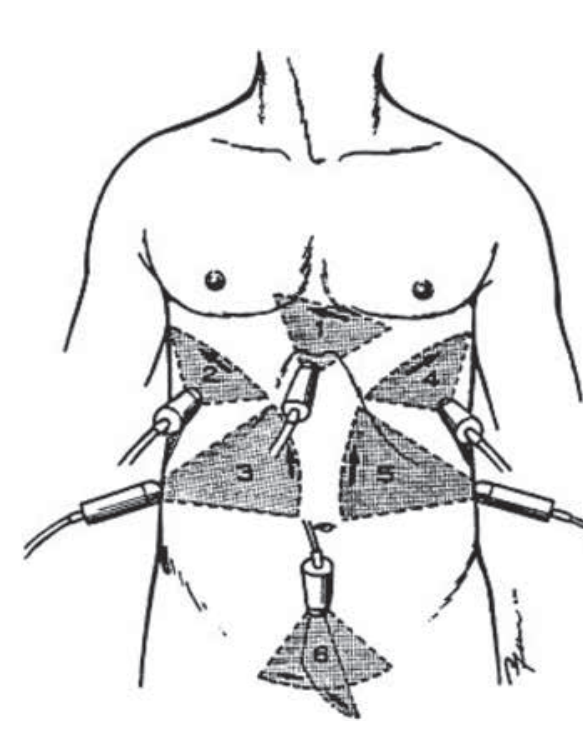

\section{FAST}

1 - pericardium

2 - a right upper

quadrant view to

evaluate Morison's

pouch

4 - a left upper quadrant

view to evaluate the

splenorenal recess

6 - a suprapubic view

of the pouch of Douglas pouch

Extended FAST (E-fast)

3 - a right paracolic

gutter view

5 - a left paracolic gutter view

Fig. 2. FAST and E-FAST anatomical references (26)

Other modalities, such as MRI with MR cholangiopancreatography (MRCP), hepato-biliary scintigraphy, and endoscopic retrograde cholangiopancreatography (ERCP) may require for detecting subacute or delayed complications, such as bile duct leaks, bilomas, and biliary strictures.(27)

\section{Treatment options}

Nonoperative management. The Eastern Association for the Surgery of trauma recommends that all hemodynamically unstable patients after blunt abdominal trauma should underwent surgery (Level 1 recommendations), however the same recommendations says that routine laparotomy in not indicated in the hemodynamically stable patient without peritonitis after blunt hepatic injury (Level 2 recommendation). It has been proven that nonoperative management of blunt liver injury can be effective in more than $80 \%$ of cases. (4) The careful observation by surgeon and intensive care team with repeated ultrasound, blood tests and CT (high grade injury) can be the key to successful outcome.

Indications for nonoperative management. (20)

- Hemodynamic stability

- $\quad$ No signs of peritonitis

- Ability to follow serial physical examinations (patient is conscious)

- Absence of other intraperitoneal injuries by CT scan.

- Minimal transfusion requirements 2 units of packed red blood cells (PRBCs)

Complications. Liver related complications - bile leak, hepatic abscess, hepatic necrosis, missed hollow viscus injury and haemobilia, delayed bleeding. Nonliver-related complications - pneumonia, bacteraemia, urinary tract infections, adult respiratory distress syndrome, upper gastrointestinal bleeding, multiple organ failure, compartment syndrome and sepsis.

Hepatic arterial embolisation. Sclafani (1985) demonstrated that angiography and embolization could be used to control haemorrhage from injuries to the liver and spleen. Twelve years later Hagiwara and colleagues stated that this method is an effective alternative to surgery. They concluded that almost all severe hepatic venous bleeding is self-limiting, and angiographic methods are suitable to treat haemorrhage secondary to blunt or penetrating trauma, including iatrogenic arterial injuries resulting from biliary interventions.(18) Indications for hepatic embolisation:

- Continuous haemorrhage who remain borderline after resuscitation

- Early ongoing bleeding after primary surgical haemostasis

- After damage control laparotomy

- Rebleeding after initially successful embolization

- Other vascular injuries to the liver, such as pseudoaneurysm or arteriovenous fistulae, and increased risk of delayed bleeding

Complications-hepaticpseudoaneurysm, arterioportal or arteriovenous fistulas, delayed haemorrhage, hepatic abscess and necrosis. Capsular retraction, calcifications, or segmental bile duct obstruction may be observed.

\section{Operative management}

Simple liver injuries (grades I and II)

Options for the small liver lacerations (up to $3 \mathrm{~m}$ ) suture hepatorrhaphy using horizontal mattress sutures, electro cautery or argon beam coagulation or application of adhesive sponge. All open bile ducts and blood vessels must be ligate in order to avoid complications.

\section{Complex liver injuries (grade III or greater)}

Perihepatic packing (Figure N3,(17)) is the workhorse of surgery for hepatic trauma and is especially useful for high-grade lacerations or parenchymal disruptions. Liver packing often is the only way to save the patient's life in the cases of the severe liver injury. Leading goal of the packing is homeostasis by compressing the bleeding parenchyma between packs placed above and below it. (8) 


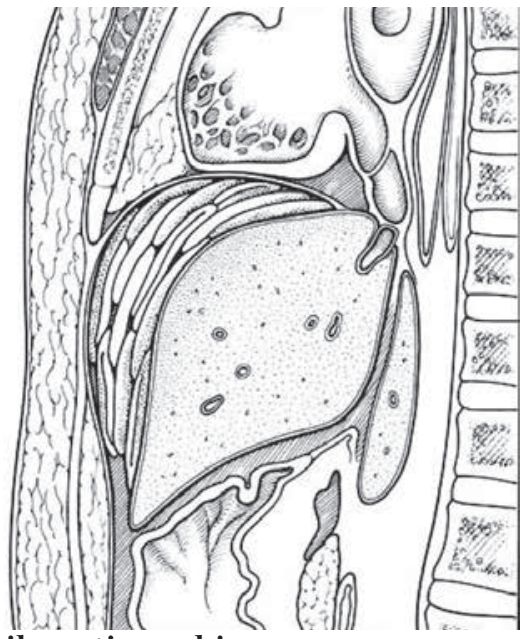

Fig. 3. Perihepatic packing

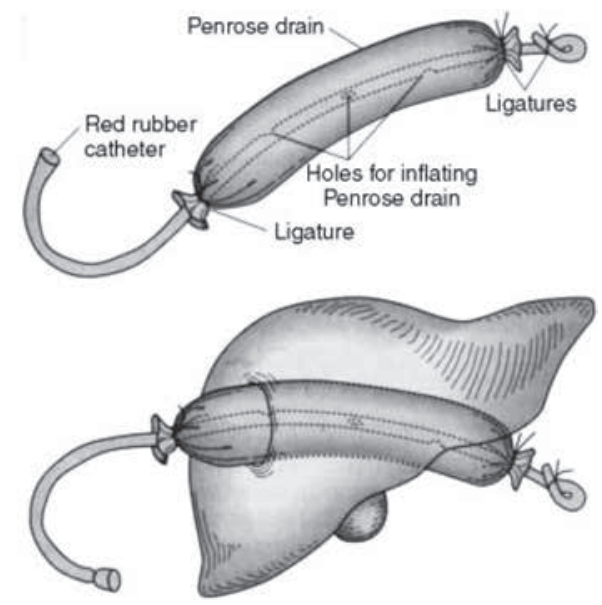

Fig. 4.Internal tamponade using a red rubber catheter and Penrose drain. (26)

Repeated surgery is recommended after hemodynamic stabilization of the patients and recovery of the coagulopathy and acidosis. In general, it is carried out 36 to 48 hours after the injury, but also can be performed within 72 hours. Early removal of the packs can promote repeated bleeding and in such cases must be done re-packing. Leaving the pack for more than 72 hours raise the risk of septic complications. If the packed liver injury is associated with damage control of a bowel injury, intestinal reconstruction should be performed, and the packs should be removed last.(14)

Internal tamponade (Figure N4,(24)). Haemostasis in case of deep lacerations or penetrating liver injury can be done using a tamponade principle. The most convenient way is insertion of a tube (Large chest tube or Foley catether) with a firmly attached balloon or rubber glove that can be inflated. Sengstaken Blakemore tube or condom can be also used.(10)

Injuries to the retrohepatic IVC or hepatic veins. Techniques for repair of these injuries require methods to decrease blood flow through this area and include total vascular isolation of the liver (clamping the hepatoduodenal ligament, suprarenal IVC and suprahepatic IVC), use of a transatrial chest tube or endotracheal tube shunts, and venovenous bypass.

Resectional debridement. This method involves removal of damaged tissue till the border of the healthy tissues and provides atypical resection of damaged liver, rather than anatomical resection. All blood vessels and segmental bile ducts must be ligated. Difficult bleeding control is the technical drawback to this method and often ended up with liver packing.(1)(3)

Hepatic resection refers to anatomic removal of a segment (or lobe) and is reserved for patients with total destruction of a segment (or lobe) or when needed to control exsanguinating haemorrhage. Formal resection is rarely used in the trauma setting as it carries a high mortality rate.(6)

Selective hepatic artery ligation can be used to control arterial haemorrhage from the liver parenchyma. This technique is usually allowed because of the high oxygen saturation of the portal blood and can be performed without subsequent hepatic necrosis. It is indicated in the rare instance when selective clamping of an extrahepatic artery causes cessation of arterial bleeding in a hepatotomy or laceration and the bleeding vessel cannot be seen inside the liver.

\section{CONCLUSIONS}

Management of blunt abdominal trauma still remains a significant challenge. Recent experience shows that hemodynamically stable patients should undergo CT scan to exclude additional injuries. NOM is recommended for HD stable patients with CT confirmed liver injury without signs of active bleeding and peritonitis.

\section{Conflict of interest: None}

\section{REFERENCES}

1. Atlasof Trauma/ Emergency Surgical Techniques William G. Cioffi, Juan A. Asensio, Charles A. Adams, Michael D. Connoly, Walter L. Biffl, Gregory J. Jurkovich, and L.D. Britt, Chapter 14, $155-164$

2. Cogbill TH, Moore EE, Jurkovich GJ, Feliciano DV, Morris JA, Mucha P. Severehepatic trauma: a multi-center experiencewith 1335 liverinjuries // J Trauma 1988; 28: 1433-8.

3. Cox E.F., Flanchbaum L., Dauterieve A.H., etalBlunt trauma to theliver. Analysis of management and mortality in 323 consecutive patients // AnnSurg 1988; 207: 126 - 129 CrossRef

4. EmergencyRadiology: The Requisites // Jorge A. Soto, andBrian C. Lucey, Chapter 3, $79-111$

5. Finkelstein EA, Corso PS, Miller TR, Associates. Incidence and Economic Burden of Injuries in the United States // NewYork, NY: Oxford University Press; 2006

6. Hepatobiliary and Pancreatic Surgery, Fifth Edition 2014. O. James Garden, and Rowan W. Parks 17, 304-325 
7. http://data.csb.gov.lv/Table.aspx?layout= tableViewLayout $1 \delta$ px_tableid=TR0070.px\&px_ path=transp_Ikgad $\%$ c4 $\% 93$ jie $\% 20$ statistikas $\% 20$ dati__ Transports $\delta$ p x_language $=\operatorname{lv} \delta$ p $x_{-}$ $\mathrm{db}=$ transp\&rxid=09cbdccf-2334-4466-bdf7005lbadldecd

8 http://faculty.ksu.edu.sa/bismar/Pictures \% 20 Library/Forms/DispForm.aspx?ID $=114$

9. http://www.cdc.gov/injury/overview/leading_cod. html

10. Morimoto RY, Birolini D, Junqueira AR Jr, etal: Balloon tamponade for transfixing lesions of the liver // SurgGynecolObstet, 164:87-88, 1987

11. Murray CJ, Lopez AD. Alternative projections o fmortality and disability by cause 1990-2020: Global Burden of Disease Study // Lancet, 1997; 349(9064): 1498-504

12. Nasim Ahmed and Jerome J Vernick, Manage-ment of liver trauma inadults // J Emerg Trauma Shock, 2011, Jan-Mar; 4(1): 114-119

13. NCIPC: Web-based InjuryStatistics Query and Reporting System (WISQARS)http://www.cdc.gov/ injury/wisqars

14. Nicol AJ: Packing for control of hemorrhage in major liver trauma // World J Surg, 2007; 31 : 569 574 CrossRef

15. Stassen $\mathrm{NA}^{1}$, Bhullar I, Cheng J Detal, Nonoperative management of blunt hepatic injury: an Eastern Association for the Surgery of Trauma practice management guideline // J Trauma Acute Care Surg, 2012 Nov;73

16. Operative Management of Adult Blunt Hepatic Trauma // The Journal of TRAUMA® Injury, Infection, and Critical Care • Volume 71, Number 1 , July 2011

17. Pachter HL, Liang HG, Hofstetter SR: Liver and biliary trauma. Moore EE, Mattox KL, Feliciano DV (eds) // Trauma, 2nd ed. East Norwalk, CT

18. Park RW, Chrysos E, Diamond T, Management of liver trauma // Br J Surg, 1999;86:1121-35
19. Alexander L. Eastman, David H. Rosenbaum and Erwin R. Thal // Parkland Trauma Handbook, The Third Edition, 27, 210-22

20. Polanco P., Leon S., Pineda J., et al Hepatic resection in the management of complex injury to the liver // J Trauma, 2008; 65: $1264-1269$

21. Ramia JM, Ramiro C, De la Plaza R, etal, Complications Associated with Non-Operative Management of Blunt HepaticInjury: a Review // The Open Emergency Medicine Journal, 2013, 5 , 8-11

22. Salomone Di Saveriol, Ernest E Moore, GregorioTugnolietal, Nonoperative management of liver and spleen traumatic injuries: a gigant withclay feet // World yournal of emergency surgery, 23 January 2012

23. Scalea M.T., Rodriguez A., Chiu W.C., etal Focussed assessemnet with sonography for trauma (FAST): results from an international consensus conference // J Trauma, 1999; 45: 466 - 472 CrossRef

24. Scottetal, 2006. Scott BG: Early agressive closure of the open abdomen // J Trauma, 2006; 60: 17 - 22

25. K.H. Liaul, L.H. Blumgart, R.P. DeMatteo, Segment-oriented approach to liver resection // Surgical clinics of North America, 2004, 543-544

26. Susthers S.E., Albrecht R., Foley D., et al Surgeon directed ultrasound for trauma is a predictor of intraabdominal injury in children // Am Surg, 2004; 70: $164-167$

27. Yen K, Gorelick MH. Ultrasound applications for the pediatric emergency departament: a review of the current literature // Pediatric Emergency Care, 2002; 18 (3):226 - 34

\section{Address:}

Solvita Stabina

Talavas gatve 13 - 8, Riga, Latvia

E-mail: solvita.stabina@inbox.lv 